\title{
Epidemiology of allergic rhinitis in Quebec: from a 2008 population-based survey
}

\author{
M. Canuel, MSc; G. Lebel, MSc
}

This article has been peer reviewed.

\begin{abstract}
Introduction: Our objective was to estimate the prevalence of symptoms and the proportion of a lifetime physician-based diagnosis of allergic rhinitis (AR) in the province of Quebec among people aged 15 years and older.
\end{abstract}

Methods: The 2008 Quebec Population Health Survey provided data on the prevalence of symptoms and proportion of lifetime physician-based diagnoses of AR. The prevalence of symptoms was defined as the proportion of individuals who, in the absence of a cold or the flu, had nasal and ocular symptoms in the 12 months before the survey.

Results: The reported prevalence of AR symptoms was 17\%, although 9\% did not have a diagnosed condition. Reported prevalence was lowest in those aged 65 years and older $(12 \%)$ and was more common among women $(19 \%)$ than men $(15 \%)$. The estimated prevalence of lifetime physician-based diagnosis was $17 \%$.

Conclusion: AR prevalence is high in Quebec with about 1 in 6 people experiencing symptoms. The condition is underdiagnosed and might also be undertreated.

Keywords: adult, allergic rhinitis, allergy, diagnosis, prevalence, rhinoconjunctivitis, symptoms

\section{Introduction}

Allergic rhinitis (AR) occurs as a result of exposure to allergens that induce inflammation of the nasal mucosa, causing nasal symptoms (e.g. sneezing, runny or blocked nose). The small size of some allergens (e.g. pollen) facilitates their penetration of the ocular mucosa causing ocular symptoms (e.g. itching, watering).

Many allergens are associated with AR symptoms and sensitization to these allergens differs between geographical regions. A United States study of 53 allergens showed that among atopic individuals, positive results were more frequent for graminae, tree pollen, dust mites and ragweed. ${ }^{1}$ A similar investigation among people who consulted an asthma and allergy clinic in Québec City resulted in different findings, with allergic reactions more frequently linked to indoor allergens (e.g. dogs, cats and dust mites). ${ }^{2}$ Allergic reactions to more than one allergen are cited above, the average number of positive tests per person among the 53 allergens tested ranged from 5 for 70 - to 79-year-olds to 13 for 10 - to 19 -year-olds.

The prevalence of AR is increasing in several countries, especially in those with low or moderate rates. ${ }^{3}$ We did not find any studies that estimated the prevalence of AR in adults in each region in Quebec. However, one common. ${ }^{1,2}$ In the Calabria et al. ${ }^{1}$ study investigation estimated the prevalence of AR symptoms in Montréal at 19\% in $1995 .{ }^{4}$ In Quebec, the main allergens responsible for AR symptoms are pollens. The Quebec Social and Health Survey of 1998 estimated that $10 \%$ of the Quebec population had hay fever (AR caused by pollen). ${ }^{5}$

The objective of our study was to estimate the prevalence of AR symptoms and the proportion of AR diagnosis in the province of Quebec among people aged 15 years and older.

\section{Methods}

\section{Survey}

The 2008 Quebec Population Health Survey (QPHS) was a questionnaire-based survey that collected information for the national surveillance plan. The survey, conducted by the Quebec Statistic Institute (QSI), covered different health matters and included 218 questions. The survey had a complex design, and the target population included people aged 15 years and older living in private households in Quebec. The sample size was chosen to obtain acceptable precision (coefficient of variation $\leq$ $15 \%$ ) for a low prevalence of $2.8 \%$ at the regional level. The global response rate was about $58 \%$ with 38154 people completing the telephone questionnaire, which was administered over 13 months (February 2008-March 2009) to take into account seasonal variation. The survey was representative of 6326523 people aged 15 years and older, corresponding to $97 \%$ of the population for that age group (two northern regions were excluded). ${ }^{6}$

\section{Author references:}

Institut national de santé publique du Québec (INSPQ), Québec, Quebec, Canada

Correspondence: Magalie Canuel, INSPQ, 945, avenue Wolfe, 4 e étage, Québec, QC G1V 5B3; Tel.: 418-650-5115, ext. 5224; Fax: 418-654-3144; Email: magalie.canuel@inspq.qc.ca 


\section{Questionnaire}

Table 1 shows the QPHS questions on AR. Questions Q2 to Q5 were based on the validated International Study of Asthma and Allergies in Childhood (ISAAC) survey questionnaire. ISAAC is an international investigation that provides estimates of $A R$ in children from nasal (Q2) and ocular (Q3) symptoms. ${ }^{7 * *}$ The QPHS also assessed the months during which symptoms flared (Q4) and limitations of daily activities (Q5). Questions Q6 and Q7, which are not from ISAAC, provide information on factors that trigger symptoms (pollen, animal allergens or dust mites) and on lifetime physician-based diagnosis. The questionnaire was available in French and English; $83 \%$ of the sample population spoke only French at home. ${ }^{6}$

\section{Definitions}

The prevalence of AR symptoms is defined as the proportion of individuals who answered "yes" to both Q2 and Q3, that is, those who reported nasal symptoms (sneezing, nasal congestion, runny nose) and ocular symptoms (itchy, watery eyes) in the absence of a cold or the flu. The prevalence of physician-based diagnoses of AR consists of individuals who answered in the affirmative to having been told by a physician that they had AR (Q7a), hay fever (Q7b) or a ragweed allergy (Q7c) during their lifetime (see Table 1).

We based the proportion of individuals who had seasonal symptoms (i.e. over 1 to 6 months, continuous or not) as opposed to those who had perennial symptoms (i.e. over 7 months) on answers to Q4.

\section{Statistical analysis}

The Quebec Public Health Infocentre provided data for this study using SAS version 9.1 statistical software (SAS Institute Inc., Cary, NC, US) and the 2008 QPHS database. The Infocentre provides online access to standardized results of indicators defined in the surveillance plan to public health stakeholders.

The QSI used the hot deck imputation method to impute the respondent's age (3\% of missing data) and a linear regression model to impute the household category of income ( $32 \%$ of missing data). All percentages were weighted to represent population estimates. As a result, we do not show sample sizes in this manuscript. Proportions had coefficients of variation of $15 \%$ or less unless otherwise stated. Because of the complex sampling design, bootstrap weights, provided by QSI, were used to estimate unbiased precisions on proportion ${ }^{8}$ and to estimate $95 \%$ confidence intervals (CIs) using the 2.5 and 97.5 percentile of the 2000 bootstrap weights distribution. Bootstrap weights were also used in comparing two proportions. First, the difference between the two proportions was calculated for the 2000 bootstrap weights. The differences in the 2000 proportions were placed in order and a $95 \%$ CI with the 2.5 and 97.5 percentiles of the difference distribution built. The difference between two proportions was deemed statistically significant if the CI did not include the null value.

Non-response was estimated as the weighted ratio of the number non-responders to the total number of subjects. Data in this manuscript are mainly descriptive: no adjustment was made for age or gender.

\section{Results}

\section{Prevalence of allergic rhinitis symptoms}

In 2008, $17 \%$ of the Quebec population 15 years and older had symptoms of AR during the previous 12 months. The prevalence was significantly lower (12\%) in

\section{TABLE 1}

English version of questionnaire on AR in the Quebec Population Health Survey, 2008

\begin{tabular}{|c|c|c|}
\hline Question & & Available answers \\
\hline Q2 & $\begin{array}{l}\text { In the past } 12 \text { months, that is, the period beginning on (date } 12 \text { months ago) and } \\
\text { ending yesterday, did you have episodes of sneezing, or have a dripping or stuffy nose } \\
\text { when you did not have a cold or flu? }\end{array}$ & $\begin{array}{l}\text { Yes / no (go to Q7a) / does not know (go to Q7a) / } \\
\text { no response (go to Q7a) }\end{array}$ \\
\hline Q3 & In the past 12 months, were these nasal problems accompanied by watery and itchy eyes? & Yes / no \\
\hline Q4 & $\begin{array}{l}\text { During which month or months over the past } 12 \text { months did you have } \\
\text { these nasal problems? }\end{array}$ & $\begin{array}{l}\text { January; February; March; April; May; June; July; August; } \\
\text { September; October; November; December; All the months } \\
\text { of year }\end{array}$ \\
\hline Q5 & During the past 12 months, did these nasal problems limit your daily activities? & Not at all / a little / somewhat / a lot \\
\hline Q6 & $\begin{array}{l}\text { Did the following elements usually trigger or increase these nasal problems? } \\
\text { a) Dust mites or house dust; } \\
\text { b) Pollen; } \\
\text { c) Animals; } \\
\text { d) Are there other elements (causes) that usually trigger or increase these nasal } \\
\text { problems? If yes, Specify. }\end{array}$ & Yes / no \\
\hline Q7 & $\begin{array}{l}\text { Has a doctor ever told you that: } \\
\text { a) You have allergic rhinitis? } \\
\text { b) You have hay fever? } \\
\text { c) You are allergic to ragweed? }\end{array}$ & Yes / no \\
\hline
\end{tabular}

\footnotetext{
* ISAAC includes ocular symptoms as part of its assessment of AR.
} 
TABLE 2

Prevalence of AR symptoms and proportion of physician-diagnosed AR in the Quebec population, $\geq 15$ years, by age and sex, 2008

\begin{tabular}{|c|c|c|c|c|}
\hline \multirow[t]{2}{*}{ Characteristics } & \multicolumn{2}{|c|}{ AR symptoms in previous 12 months } & \multicolumn{2}{|c|}{ Lifetime physician-diagnosed AR } \\
\hline & $\%(95 \% \mathrm{Cl})$ & Non-response, \% & $\%(95 \% \mathrm{Cl})$ & Non-response, $\%$ \\
\hline \multicolumn{5}{|l|}{ Age, years ${ }^{\mathrm{a}}$} \\
\hline $25-44$ & $19.6(18.3-20.9)$ & 0.9 & $20.9(19.5-22.2)$ & 1.7 \\
\hline $45-64$ & $16.8(15.8-17.9)$ & 0.9 & $16.2(15.2-17.3)$ & 1.9 \\
\hline Women & $19.1(18.1-20.0)$ & 0.9 & $18.3(17.4-19.3)$ & 2.1 \\
\hline Men & $14.5(13.5-15.5)$ & 1.1 & $15.3(14.3-16.3)$ & 1.6 \\
\hline Total & $16.8(16.2-17.5)$ & 1.0 & $16.8(16.1-17.5)$ & 1.9 \\
\hline
\end{tabular}

Abbreviations: AR, allergic rhinitis; $\mathrm{Cl}$, confidence interval.

${ }^{a}$ Differences for all age groups are statistically significant except for 15-24 and 45-64 year age groups.

b Differences in prevalence between all pairs are statistically significant.

the elderly ( $\geq 65$ years), and significantly higher in women (19\%) than in men (15\%) across all age groups (Table 2).

The prevalence of AR symptoms increased significantly with education level, from $13 \%$ among those with no high school diploma to $16 \%$ for those who had completed high school and 19\% for those who had completed college or university (19\% and 20\%, respectively) (Table 3).

The difference in prevalence of AR symptoms in income quintiles was not statistically significant (Table 3 ).

\section{Other features of allergic rhinitis among people with symptoms}

The survey asked respondents which month or months in the previous 12 they had experienced AR symptoms. The proportion with symptoms during the summer (June, July or August) was the highest (50\%), followed by those with symptoms in spring (March, April or May; 41\%). The proportion was lowest $(12 \%)$ in winter (December, January or February) (Table 4).

The most frequently reported allergen among the 3 triggers listed was pollen

TABLE 3

Prevalence of AR symptoms in the previous 12 months in the Quebec population, $\geq 15$ years, by level of education and income, 2008

\begin{tabular}{lcc} 
& \multicolumn{1}{c}{ AR symptoms in previous 12 months } \\
\cline { 2 - 3 } & $\%(95 \% \mathrm{CI})$ & Non-response, \% \\
\hline Education $^{\mathrm{a}}$ & $12.8(11.7-13.9)$ & 1.4 \\
$<$ Secondary school & $15.6(14.4-16.8)$ & 1.1 \\
Secondary school graduate & $19.2(17.8-20.7)$ & 0.8 \\
College graduate & $19.8(18.2-21.5)$ & 0.6 \\
University graduate & $16.4(14.8-18.2)$ & 1.0 \\
Income & $16.0(14.6-17.5)$ & 1.5 \\
$1^{\text {st }}$ quintile (low) & $17.6(16.0-19.2)$ & 0.9 \\
$2^{\text {nd }}$ quintile & $17.0(15.4-18.6)$ & 0.5 \\
$3^{\text {rd }}$ quintile & $18.0(16.4-19.7)$ & 0.5 \\
$4^{\text {th }}$ quintile & $16.8(16.2-17.5)$ & 1.9 \\
$5^{\text {th }}$ quintile (high) & & \\
Total & & \\
\hline
\end{tabular}

Abbreviations: AR, allergic rhinitis; $\mathrm{Cl}$, confidence interval.

${ }^{a}$ Differences between all groups are statistically significant except those with college and university degrees.
(76\%), followed by dust mites (55\%) and animal allergens (40\%). Over 64\% reported at least 2 triggering factors, while $31 \%$ reported only 1 (Table 4 ).

The symptoms of the majority $(77 \%)$ of people with AR did not limit them in their daily activities. However, 9\% were moderately or severely limited in their daily functions (Table 4).

The majority of people with AR had seasonal symptoms, either over a consecutive or non-consecutive period of 1 to 3 months $(61 \%)$ or 4 to 6 months $(16 \%)$. Just under a quarter (23\%) had perennial symptoms (7 to 12 months) (Table 4 ).

\section{Lifetime prevalence of physician-based allergic rhinitis diagnosis}

The lifetime prevalence of a physicianbased diagnosis of AR in the study population 15 years and older was $17 \%$. Prevalence was higher in women (18\%) than in men $(15 \%)$, and also higher in 25 to 44 -year-olds $(21 \%)$ and lower in those aged 65 years or over $(9 \%)$ (Table 2 ).

\section{Comparison between prevalence of symptoms and prevalence of physician- based allergic rhinitis diagnosis}

We observed that individuals who had symptoms of AR (17\%) were not necessarily the ones who had a physician-based diagnosis of AR (17\%) (Figure 1). Only 
TABLE 4

Distribution of the study population, $\geq 15$ years, with AR symptoms in previous 12 months, Quebec, 2008

\begin{tabular}{|c|c|c|}
\hline & \multicolumn{2}{|c|}{ Distribution of population with AR symptoms } \\
\hline & $\%(95 \% \mathrm{Cl})$ & Non-response, $\%$ \\
\hline Season $^{\mathrm{a}}$ & & 6.9 \\
\hline Summer (June, July, August) & $49.9(47.5-52.1)$ & \\
\hline Spring (March, April, May) & $41.3(39.1-43.5)$ & \\
\hline Fall (September, October, November) & $30.2(28.1-32.3)$ & \\
\hline Winter (December, January, February) & $12.1(10.6-13.5)$ & \\
\hline \multicolumn{3}{|l|}{ Triggers $^{\mathrm{a}}$} \\
\hline Pollen & $75.5(73.4-77.5)$ & 6.0 \\
\hline Dust mites & $55.5(53.1-57.7)$ & 8.8 \\
\hline Animal allergens & $40.0(37.7-42.4)$ & 5.2 \\
\hline Number of triggers ${ }^{b, c}$ & & 15.2 \\
\hline 1 & $31.0(28.7-33.3)$ & \\
\hline 2 & $29.6(27.5-31.8)$ & \\
\hline$\geq 3$ & $34.7(32.3-37.0)$ & \\
\hline Limitation of daily activities ${ }^{d}$ & & 1.3 \\
\hline Not at all & $77.2(75.3-79.0)$ & \\
\hline A little & $13.6(12.1-15.3)$ & \\
\hline Somewhat & $6.3(5.3-7.3)$ & \\
\hline A lot & $2.9(2.2-3.7)$ & \\
\hline Duration $^{\mathrm{d}}$ & & 6.9 \\
\hline Seasonal: $1-3$ months & $60.5(58.3-62.6)$ & \\
\hline Seasonal: 4-6 months & $16.2(14.7-17.9)$ & \\
\hline Annual: 7-12 months & $23.3(21.6-25.2)$ & \\
\hline
\end{tabular}

Abbreviations: AR, allergic rhinitis; $\mathrm{CI}$, confidence interval.

a No statistical test was performed.

b From a list of 3 triggers and open response to others.

c Only 2 categories are statistically different, i.e. 2 and $\geq 3$ triggering factors.

${ }^{d}$ Differences between all pairs are statistically significant.

$7 \%$ of the study population had symptoms and had ever been diagnosed with AR; 9\% had symptoms but no diagnosis. Another
$10 \%$ had a physician-based diagnosis without declaring any symptoms during the previous 12 months. When these proportions are combined, the true prevalence of AR could be as high as $26 \%$ $(9 \%+7 \%+10 \%)$ (Figure 1$)$.

\section{Discussion}

The 2008 QPHS is the most comprehensive survey conducted on AR in Quebec. The results are also representative of the population of individuals aged 15 years and older in this province. However, the survey did not include residents in residential care who generally have a poor physical health. This may result in underestimating the prevalence of some diseases. Nevertheless, we have no reason to believe that the prevalence of AR would be higher in the excluded population.

Non-responses to most questions were less than $5 \%$. In those cases, the risk of bias is considered low. Non-response was higher for questions on months of symptoms (season and duration) as well as for the triggers. Non-response for AR timing might be as a result of a memory bias as the person had to recall symptoms over the previous 12 months. For triggering factors, including the number of allergens, the non-respondents might be unaware of their AR triggers. This may be because of the high proportion of undiagnosed individuals since clinical tests scheduled as a result of medical diagnoses often identify the triggering factors.

Although both the prevalence of symptoms and that of lifetime physician-diagnosed AR were similar (17\% each), our analysis showed that only $7 \%$ of the population

FIGURE 1

Combined AR prevalence of people with symptoms in previous 12 months and those who received a lifetime physician-based diagnosis of AR, Quebec, 2008

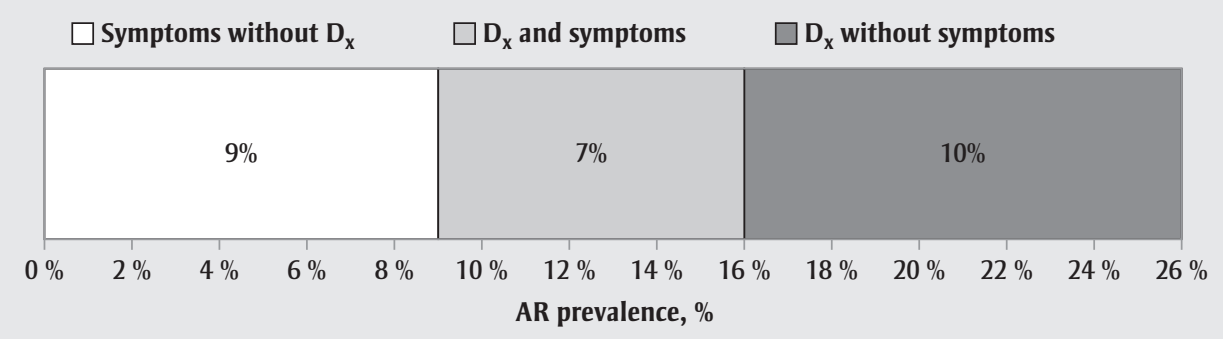

Abbreviations: AR, allergic rhinitis; $\mathrm{D}_{\mathrm{x}}$, diagnosis. 
with symptoms had ever had a physician diagnose their AR. The proportion of undiagnosed AR was estimated to be $56 \%$ among those with symptoms, which corresponded to $9 \%$ of the study population 15 years and older with undiagnosed AR. This situation may be explained in part by the fact that overthe-counter medication to treat symptoms of AR is readily available and people who have symptoms can receive advice from their pharmacist.

Around $10 \%$ of the population aged 15 years and older who were asymptomatic in the previous 12 months had been diagnosed as having AR by a physician. This lack of symptoms may be because their physicians advised them of preventive and protective measures, including reducing exposure to allergens, or on treatment (e.g. intranasal glucocorticosteroids, immunotherapy). ${ }^{9}$

The measure of the proportion of people with an AR diagnosis underestimates the true prevalence of AR as $9 \%$ had symptoms without ever having a positive diagnosis. On the other hand, the measure of the prevalence of symptoms also underestimates the true prevalence of $\mathrm{AR}$ as $10 \%$ of our study population had been diagnosed despite not having any symptoms. Combining these two proportions may provide a better picture of $\mathrm{AR}$ in Quebec. The proportion of physiciandiagnosed AR in our population was $17 \%$, but the true prevalence of AR could have been as high as $26 \%$ when we include those with symptoms but no physician-based diagnosis. This proportion is similar to an estimate of $17 \%$ to $29 \%$ (depending on the country) based on the results of a survey with clinical testing performed in five European countries. ${ }^{10}$ However, some non-allergic conditions such as infections, hormonal imbalance and exposure to physical agents can cause similar ocular and nasal symptoms, ${ }^{9}$ indicating that the prevalence of $\mathrm{AR}$, symptomatic or otherwise, is unlikely to be as high as $26 \%$.

Our results showed that the prevalence of AR symptoms increased with level of education. We cannot explain the reason for this. In Canada, income is associated with level of education. ${ }^{11}$ Nevertheless, the prevalence of AR symptoms did not vary significantly with income. Most studies tested socioeconomic status and one estimated a lower prevalence of allergies among people with lower education status in the United States in $1978 .^{12}$ Misunderstanding questions is unlikely to have been the reason for any errors among survey respondents since our questions were based on the French and English versions of the ISAAC children's questionnaire and our respondents were aged 15 years and older.

Although most studies found the prevalence of AR to be higher in children and youth (i.e. those aged 16-24 years), ${ }^{13}$ others found prevalence to be higher in older age groups, ${ }^{1,14}$ as did we among 25to 44-year-olds.

Pollen (76\%) was the allergen most often reported as the factor triggering survey respondents' symptoms. Similarly, Schatz ${ }^{15}$ found pollen to be the triggering factor among $78 \%$ of those with physiciandiagnosed AR in the United States. We found that $64 \%$ of people with AR symptoms reported more than one triggering factor, which is similar to results from another Quebec study that found that $53 \%$ of people with allergies had skin reactions to more than one allergen. ${ }^{2}$

We found the proportion of people limited in their daily activities by symptoms of AR (23\%) to be similar to that estimated in the United States $(15 \%-25 \%)^{16}$ where it was also found that $38 \%$ of people with AR could not tolerate their symptoms without using some medication. ${ }^{16}$ Schatz ${ }^{15}$ found that half of those diagnosed with AR could not control their symptoms, even though most took at least 2 different medications. In Quebec, the cost associated with AR associated with ragweed was estimated at \$156 million, of which $\$ 33$ million were spent on medications. $^{17}$

\section{Conclusion}

AR is common in Quebec, affecting at least $17 \%$ of the population aged 15 years and older. It is underdiagnosed and might be undertreated, as $16 \%$ of people with AR symptoms had seasonal symptoms over a period of 4 to 6 months. This is the first survey to estimate AR prevalence in Quebec and our results are not comparable to other Quebec surveys that mainly focused on hay fever. The combined prevalence of symptoms and lifetime physician-based diagnosis of AR estimated in this study should provide a baseline for future investigations in the same population.

\section{Acknowledgements}

The authors thank Marc-André Dubé and Suzanne Gingras from the Institut national de santé publique du Québec (INSPQ) for their statistical analysis and support. They also thank all the people in the QPHS who helped with the project.

\section{References}

1. Calabria CW, Dice JP, Hagan LL. Prevalence of positive skin test responses to 53 allergens in patients with rhinitis symptoms. Allergy Asthma Proc. 2007;28:442-8.

2. Boulet LP, Turcotte H, Laprise C, et al. Comparative degree and type of sensitization to common indoor and outdoor allergens in subjects with allergic rhinitis and/ or asthma. Clin Exp Allergy. 1997;27:52-9.

3. Asher MI, Montefort S, Bjorksten B, et al. Worldwide time trends in the prevalence of symptoms of asthma, allergic rhinoconjunctivitis, and eczema in childhood: ISAAC Phases One and Three repeat multicountry cross-sectional surveys. Lancet. 2006;368: 733-43.

4. Goulet L, Christin C, Hudon É. Prévalence et gravité des symptômes d'allergie respiratoire chez les résidants de l'île de Montréal: rapport d'enquête. Montreal (QC): Régie régionale de la santé et des services sociaux de Montréal-Centre; 1996.

5. Canuel M, Bélanger D. Évolution de la prévalence des allergies non alimentaires et de leur traitement par médication: données québécoises issues d'enquête populationnelles (1994-2005). Quebec (QC): Institut national de santé publique; 2010.

6. Camirand $\mathrm{H}$, Bernèche $\mathrm{F}$, Cazale $\mathrm{L}$, et al. L'enquête québécoise sur la santé de la population, 2008: pour en savoir plus sur la santé des Québécois. Quebec (QC): Institut de la statistique du Québec; 2010. 
7. Asher MI, Keil U, Anderson HR, et al. International Study of Asthma and Allergies in Childhood (ISAAC): rationale and methods. Eur Respir J. 1995;8:483-91.

8. Rust KF, Rao JN. Variance estimation for complex surveys using replication techniques. Stat Methods Med Res. 1996;5:283310.

9. Bousquet J, Khaltaev N, Cruz AA, et al. Allergic rhinitis and its impact on asthma (ARIA) 2008 update (in collaboration with the World Health Organization, GA(2)LEN and AllerGen). Allergy. 2008;63 Suppl 86:8160.

10. Bauchau V, Durham SR. Prevalence and rate of diagnosis of allergic rhinitis in Europe. Eur Respir J. 2004;24:758-64.

11. Indicators of well-being in Canada: what difference does learning make to financial security? [Internet]. Ottawa (ON): Human Resources and Skills Development Canada; 2008 Jan [cited 2013 July 19]. Available from: http://www4.hrsdc.gc.ca/.3ndic.1t.4r @-eng.jsp?iid=54

12. Pincus T, Callahan LF, Burkhauser RV. Most chronic diseases are reported more frequently by individuals with fewer than 12 years of formal education in the age 1864 United States population. J Chronic Dis. 1987;40:865-74.

13. Izquierdo-Dominguez A, Valero AL, Mullol J. Comparative analysis of allergic rhinitis in children and adults. Curr Allergy Asthma Rep. 2013 Apr;13(2):142-51.

14. Nathan RA, Meltzer EO, Derebery J, et al. The prevalence of nasal symptoms attributed to allergies in the United States: findings from the burden of rhinitis in an America survey. Allergy Asthma Proc. 2008;29:6008.

15. Schatz M. A survey of the burden of allergic rhinitis in the USA. Allergy. 2007;62 Suppl 85:9-16.

16. Allergies in America: a landmark survey of nasal allergy sufferers: adults-executive summary. Mississauga (ON): Nycomed; 2006 [cited 2013 July 19]. Available from: http://www.worldallergy.org/UserFiles/file /Allergies\%20in \%20America\%20(AIA) \%20$\% 20$ Adult $\% 20$ Executive $\% 20$ Summary.pdf
17. Tardif I. Portrait des coûts de santé associés à l'allergie au pollen de l'herbe à poux. Montérégie (QC): Agence de la santé et des services sociaux de la Montérégie; 2008. 